\title{
Validation of the Sport Multidimensional Perfectionism Scale-2 for the Mexican Sport Context
}

\author{
Antonio Pineda-Espejel ${ }^{1, *}$, Emilio Arrayales ${ }^{1}$, Raquel Morquecho-Sánchez ${ }^{2}$, Marina Trejo ${ }^{1}$ \\ ${ }^{1}$ Faculty of Sports, Autonomous University of Baja California, Mexico \\ ${ }^{2}$ Faculty of Sport Organization, Autonomous University of Nuevo Leon, Mexico
}

Copyright $\bigcirc 2017$ by authors, all rights reserved. Authors agree that this article remains permanently open access under the terms of the Creative Commons Attribution License 4.0 International License

\begin{abstract}
The aim of this study was to validate the factorial structure of a Spanish version of the Sport Multidimensional Perfectionism Scale-2 (Sport-MPS-2) for the Mexican population, and provide evidence of reliability. This scale is composed of 42 items that measure six factors of perfectionism: concern over mistakes, organization, perception parental pressure, perception coach pressure, doubts about actions, and personal standards. Such factors were suggested by the multidimensional perfectionism approach. The study involved 420 athletes of both genders with an average age of 21.63 years old $(S D=3.83)$ who answered the Mexican Spanish Version of the Sport-MPS-2. After eliminating six items, the results supported the six-factor model; and in five factors, the internal consistency exceeded or was under the limit of the usage criteria. In conclusion, the Mexican Spanish version of the Sport-MPS-2 offers factorial structure and constructs validity, excluding six items. Thus, it can be used for assessing five dimensions of perfectionism in athletes, even though further research shall be conducted to improve this instrument.
\end{abstract}

Keywords Reliability, Perfectionism, Validity, Sport

\section{Introduction}

Perfectionism is a personality trait that has become increasingly important within sport and exercise studies as a characteristic associated with adaptive and maladaptive outcomes $[1,2,3]$. It is a multidimensional construct and defined as an individual desire to reach a flawless performance, generally seeking high achievements standards established by oneself or his/her peers [4].

Perfectionism is a domain-specific concept [5]. J. Stoeber and F. S. Stoeber [6] pointed out that researchers interested in perfectionism in specific domains of life can benefit by using specific measurements of that domain. Hence, evaluating perfectionism with a sport specific instrument is determinant.
Frost, Marten, Lahart, and Rosenblate [7], from the use of the Multidimensional Perfectionism Scale (Frost-MPS)[7], measure of global perfectionism, proposed six facets representing central aspects of perfectionist cognition, affect and behavior across life domains. These are: personal standards, referring to the high standards for self-assessment; organization, concerning at the emphasis on the importance and preference by the order; concern over mistakes, alluding to react negatively at the errors and a tendency to interpret the equivalent errors to fail; parental criticism, as the tendency to perceive that they are too critical or exert much pressure to achieve these goals; doubts about action, relative tendency to worry about the quality of work; and parental expectations, as the tendency to perceive that the parents placed high goals.

An instrument designed to measure the above aspects, derived from the contributions of Frost and cols [7], within the sporting context was the Sport Multidimensional Perfectionism Scale (Sport-MPS) [8], which showed validity of construct for the dimensions that compose it: personal standards, concern over mistakes, perceived parental pressure, and perceived coach pressure. The construct perceived parental pressure, was defined as the tendency to perceive that the parents placed high goals and are too critical or exert much pressure to achieve these goals; and perceived coach pressure, was designed to represent athletes' tendencies to perceive their coaches as sources of performance pressure [9]. So it adds to the coach as a social agent source of pressure for athletes.

The Sport-MPS did not include organization or doubts about the actions facets; for which the Sport Multidimensional Perfectionism Scale-2 (Sport-MPS-2) [10] was developed to rectify the deficiency. In this instrument, the doubts about actions that reflect the level of the athletes that are uncertain or dissatisfied with the training in preparation for competition in the primary sport are defining; and organization as reflects athletes' tendencies or desires to establish and implement plans or routines that dictate their behavior prior to and during competition in their primary sport. 
Although the Frost-MPS served as the theoretical template for the creation of the Sport-MPS-2, nonetheless, it should be noted that the perceived coach pressure subscale of the Sport-MPS-2 is a domain-specific construct that is not measured by the Frost-MPS; and the organization and doubts about actions subscales of the Sport-MPS-2 are conceptualized quite differently than the similarly labeled subscales of the Frost-MPS [11].

Many studies had provided evidence of good reliability for the Sport-MPS-2 [10, 12, 13, 14]. However, its internal structure has repeatedly been reported as inconsistent. Gotwals, Dunn, Dunn and Gamache [11] after a second study from the confirmatory factorial analysis to the instrument, showed that three items did not correspond to the theorized factor. On the other hand, the Portuguese language adaptation [15] showed adequate internal consistency and factorial validity for a four-factor model (doubts about actions, personal standards-organization, perceived parental pressure, and concern over mistakes) with 24 items. Of the above, all Sport-MPS-2 subscales have been used simultaneously to help differentiate between healthy/adaptive and unhealthy/maladaptive profiles of perfectionism in sport $[16,17]$. Therefore, we propose a linguistic adaptation with all the six subscales.

Thus, the ability to adequately evaluate perfectionism is a current need to the development of sport and sport psychology sciences in general, especially in Mexico where no such instrument has been validated for sport contexts. The purpose of this study was to validate the factorial structure of a Spanish version of the Sport Multidimensional Perfectionism Scale-2 (Sport-MPS-2) for the Mexican population, and provide evidence of reliability.

\section{Methods}

\subsection{Participants}

Participating 420 athletes(189 men and 231 women) inhabitants of two regions of Mexico, northwest ( $40 \%$ of the sample) and northeast. They reported a mean age of 21.63 years old $(S D=3.83)$. Practitioners of different sports(e.g. basketball, soccer, volleyball) of the university, state, and national levels, reason why all of them were affiliated to their respective national sports federation. They had a sports experience of 7.57 years $(S D=5.24)$, and reporting train weekly average 2.30 hours $(S D=1.01)$. The sample size was determined based on the recommendations of at least 10 subjects per item of the instrument [18].

\subsection{Instrument}

We used a Mexican Spanish version of the Sport Multidimensional Perfectionism Scale-2 (Sport-MPS-2) [10] composed by 42 items, they measure six facets of perfectionism in sport: personal standards (PP; 7 items, e.g.
"Tengo metas extremadamente altas para mi en mi deporte"), concern over mistakes (COM; 8 items, e.g. "Debería molestarme conmigo mismo si cometo un error en la competición"), perceived parental pressure (PPP; 9 items, e.g. "Mis padres esperan de mí la excelencia en mi deporte"), perceived coach pressure (PCP; 6 items, e.g. "Mi entrenador establece estándares muy altos para mi en la competición"), doubts about actions (DAA; 6 items, e.g. "Antes de la competición, rara vez me siento satisfecho con mi entrenamiento") and organization (Org; 6 items, e.g. "Tengo y sigo una rutina antes de la competición"). Answers are given on a five-point Likert type- scale ( 1 = strongly disagree to $5=$ strongly agree). Each subscale score is calculated from the average of the sum of the items answers with which it is composed. Higher values in each dimension mean greater orientation in the target domain.

\subsection{Procediment}

To adapt the Sport-MPS-2 into Spanish, the strategy of reverse translation of Hambleton [19] and the guidelines for the translation and adaptation of tests from one culture to another [21] were used. For this process, the scale in English was translated into Spanish, by two translators with a high knowledge of both English and Spanish language. Then the discrepancies of the translation were discussed by three experts, making corrections in certain items until developing a first Spanish version of the instrument. Subsequently, this version was translated into English by a translator outside the research group, and the two versions were compared: the original and the translated one. This process ensured that the translation respected the coincidence of the original version of the instrument.

To analyze the validity of content, an expert reviewed the resulting version to ensure that the items were relevant, and that the wording was appropriate for the target population. Prior to the final attainment of the scale, the instrument was administered to a small group of athletes to verify the correct understanding of the items, who expressed full understanding of all sentences.

This research was conducted in accordance with ethical guidelines proposed by the American Psychological Association (APA). The first personal contact was with the coaches to request permission for the athletes who participate in the study. In the case of minor athletes, consent to participate was asked to coach. The application of the questionnaires was in presence of two interviewers to help participants for understanding the items or any doubt. It was also explained that respond to questionnaires, meant accepting voluntary participation in the research, and were informed of the anonymity of the data collected. The approximate time to complete the questionnaire was 15 minutes.

\subsection{Data Analysis}

Missing data points (at the item level) were treated in the 
same way across all samples and replaced with a score that corresponded to the mean of all other scores for items on the corresponding subscale provided by the individual [22].

Confirmatory factor analysis (CFA) with the LISREL 8.80 program [23] is performed. In line with the recommendations of Chou, Bentler and Satorra [24] were performed with the estimation procedure robust maximum likelihood (ML) to correct the lack of normality [25] on large samples (200-500 cases [26]). This offers a robust statistic $\chi^{2}$ called Satorra-Bentler scale statistics (S-B $\chi^{2}$ ) [27]. The input matrices were of covariance and the asymptotic covariance.

Indices of absolute and incremental adjustment were used to evaluate the model. The absolute indices used were the chi-square $\left(\chi^{2}\right)$. As the $\chi^{2}$ is sensitive to sample size [28], the model fit was assessed by adding incremental adjustment indices as the of non-normative fit index (NNFI), the comparative fit index (CFI), and the root mean error of approximation (RMSEA) more its interval confidence $90 \%$. For CFI and NNFI values equal to or greater than .90 indicate acceptable fit, and values equal to or less than .08 for RMSEA are considered acceptable [29]. The items were considered for elimination if their factorial weight was less than $.40[30]$.

To evaluate the differences between the settings of alternative models, modification indexes were examined. It has been suggested that differences less than or equal of .01 between values of NNFI ( $\triangle \mathrm{NNFI})$ and between values of CFI $(\triangle \mathrm{CFI})[31]$, it indicates practical differences. Meanwhile increases in value below 0.015 RMSEA between models indicate irrelevant differences [32].

Further analysis of reliability (Cronbach's alpha) was performed with the program SPSS 22.0. The characteristics of the items were analyzed by checking if the alpha of the scale increased with the elimination of some item and analyzing the corrected correlation item-total.

\section{Results}

For the six factors model with 42 items (M1), the CFA showed that the model hypothesis did not fit well with the data: $\chi^{2}(687)=2850.752, p<.001 ;$ RMSEA $=.082(90 \%$ IC $=.075-.088)$; $\mathrm{CFI}=.868 ; \mathrm{NNFI}=.858$. The factor loading of the items were significant, although the factor loading of six items were below the criterion $(\lambda>.40[30])$. These were two items of personal standards subscale ("Si no establezco los estándares más altos para mi en mi deporte, probablemente terminaré siendo un jugador de segunda categoria" and "Odio no ser el mejor en las cosas en mi deporte"); one item of doubts about action subscale ("Un pequeño fallo en la competencia, para mí es tan malo como ser un fracaso completo"); two items of perceived coach pressure subscale ("Mi entrenador espera la excelencia de mi en todo momento: tanto en entrenamiento como en competición" and "Siento que mi entrenador nunca intenta comprender completamente los errores que cometo en ocasiones"); and one of organization subscale ("Desarrollo planes que dictan cómo quiero actuar durante la competición").

Therefore, a second model (M2), which keeps the six hypothesized factors but the six items above mentioned were removed, was tested. The data fit was close to reality: $\chi^{2}(579)$ $=2292.909, p<.001 ; \mathrm{RMSEA}=.070(90 \% \mathrm{IC}=.062-.077)$; $\mathrm{CFI}=.901 ; \mathrm{NNFI}=.900$. Comparing the incremental adjustment indices between the two models (M1 and M2), the results showed better fit for the second model $(\triangle \mathrm{RMSEA}$ $=.012 ; \Delta \mathrm{CFI}=.033 ; \Delta \mathrm{NNFI}=.042)$. In the M2 all items load significantly $(p<.01)$ with factor loading above criteria (Figure 1).

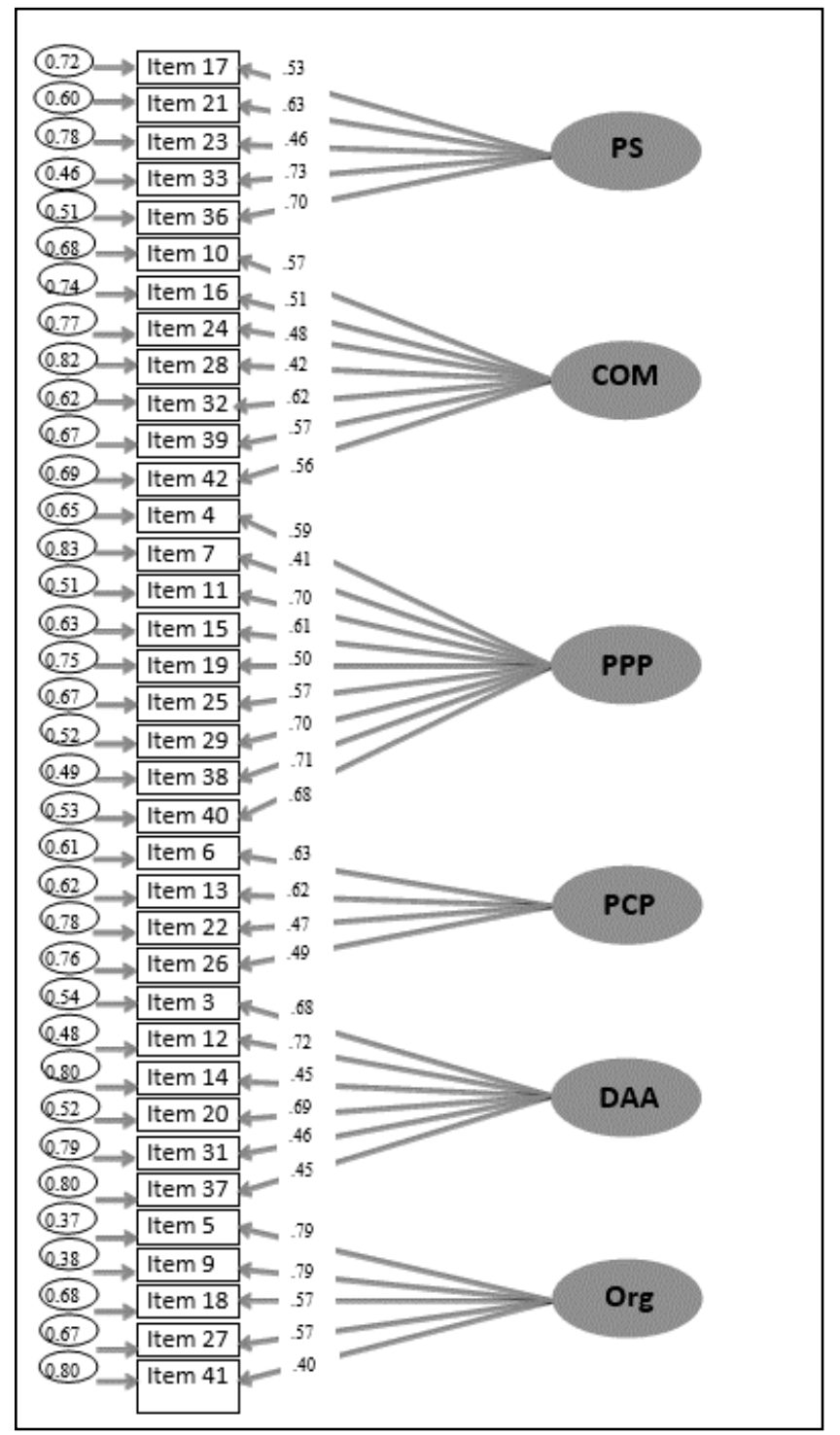

Note: All parameters are standardized and significant $(p<.01)$. In the small ellipse the error terms appear. PS: personal standards; COM: concern over mistakes; PPP: perceived parental pressure; PCP: perceived coach pressure; DAA: doubts about actions; Org: organization.

Figure 1. Estimated parameters of the Sport-MPS-2 (M2) 
Table 1. Matrix of Phi correlations and reliability of Sport-MPS-2 subscales, extracted from M2

\begin{tabular}{|c|c|c|c|c|c|c|}
\hline & 1 & 2 & 3 & 4 & 5 & 6 \\
\hline 1 PS & $(.73)$ & & & & & \\
\hline $2 \mathrm{COM}$ & $.45^{* *}$ & $(.74)$ & & & & \\
\hline $3 \mathrm{PPP}$ & $.31^{* *}$ & $.66^{* *}$ & $(.78)$ & & & \\
\hline $4 \mathrm{PCP}$ & $.26^{*}$ & $.75^{* *}$ & $.73^{* *}$ & $(.63)$ & & \\
\hline $5 \mathrm{DAA}$ & .04 & $.63^{* *}$ & $.52^{* *}$ & $.67^{* *}$ & $(.71)$ & \\
\hline 6 Org & $.38^{* *}$ & -.09 & .18 & -.02 & -.02 & $(.75)$ \\
\hline
\end{tabular}

Note: $* * p<.01 ; * p<.05$; reliability in brackets

In the second model (M2), the correlations between latent factors were lower than .80 , confirming the discriminant validity (phi $<.85$ [33]); on average, these correlations were in phi $=.36($ Min $=-.02$, Max $=.75)($ Table 1$)$. In addition, the Cronbach's alpha coefficients for internal consistency of the factors taken the second model were adequate, according to the case of psychological scales, except for the perceived coach pressure subscale (Table 1). For the internal consistency of each factor the following criteria were corroborated: a) an inter-item correlation between $r=.20$ and $r=.70$, and b) a minimum corrected correlation item-total of $r=.30$.

\section{Discussion}

With the aim to validate the factorial structure of a Spanish version of the Sport-Multidimensional Perfectionism Scale-2 (Sport-MPS-2) for the Mexican population, and provide evidence of reliability, this study was carried out.

The adequate adjustment of the hypothesized factorial structure confirms the validity of the six-factor model, which is the instrument measuring the six theorized subscales: concern over mistakes, doubts about actions, perceived coach pressure, perceived parents pressure, organization, personal standards. In addition, the items saturated significantly in their respective constructs, so it can be said that the adaptation to the Spanish spoken in Mexico of the Sport-MPS-2 has demonstrated adequate validity of its factorial structure. However, the validity is confirmed after the elimination of six items; three of them are the same as those suggested by the results of Gotwals and cols. [11] in the original English version. In addition, this adaptation in Spanish spoken in Mexico suggests eliminate three more items because the model fit, evaluated by the differences of incremental index, is significantly improved.

Six of the 42 Sport-MPS-2 items had patterns of factor loading that were questionable from an empirical-validity and theoretical-validity perspective. However, three of them have demonstrated empirical and theoretical validity in previous exploratory factor analytic studies [11]. More research is clearly required to determine if these questionable loading are a function of the idiosyncratic characteristics of this sample or whether there are inherent weaknesses with these items.
On the other hand, the matrix of phi correlations between latent factors supports that items measure different constructs. Finally, adequate internal consistency was shown for five of the six subscales, so that the precision with which the items measure the PCP is questionable. Which is opposed to the results of the original English version $[10,11]$, but may be close to those of the Portuguese version [15], since in this one the PCP factor was omitted. Although this is a domain-specific construct, and is considered one of the most influential in the sporting context $[10,34]$, more studies at instrument are necessary to accurately measure this construct. It should be noted that our results have been obtained from a robust sample, and of a similar size to that used in other studies that analyzed this instrument $[10,11,15]$.

This study has both theoretical and practical implications, as provides evidence supporting the latent model. This study of the factor structure of a version in Spanish spoken in Mexico of the Sport-MPS-2 provides indications of the instruments construct validity in the Spanish-speaking population, as well as support for the instrument to be used in the measurement of five facets of perfectionism in sport context.

From the practical point of view, the adaptation to Spanish spoken in Mexico of an instrument that measures the perfectionism in the sport is fundamental, since Dunn and cols. [5], Dunn, Causgrove Dunn, Gotwals, Vallance, Craft and Syrotiuk [35], Gotwals and cols. [2] pointed out that perfectionism is best captured by multidimensional domain-specific measures. In particular, the factorial validity of the Sport-MPS-2, including all subscales, allows the subscales be used simultaneously to help differentiate between healthy/adaptive and unhealthy/maladaptive profiles of perfectionism in sport [16, 17]. Therefore, it will be useful for coaches, sports psychologists, and Spanish-speaking researchers to measure this personality trait, and by means of which they can measure adaptive and maladaptive perfectionism in sport, as suggested Dunn and cols [36].

This work also has limitations. First, respectfully to demographics, skill level and sport types were not controlled in this study, further studies are suggested that control these variables. Second, the participants in this study were from two regions of Mexico, northwest and northeast; nevertheless may not represent psychological characteristics of other geographical areas and cultures. 
Another limitation was not to analyze the concurrent validity, so it is suggested to complement the external validity of the instrument by analyzing the association of Sport-MPS-2 factors with theoretically related constructs. Future research is needed in this area to confirm the current dimensions and items that describe the perfectionism in competitive sport participants.

\section{Conclusions}

With this study sample, the factorial and construct validity of a Spanish-language version of the Sport-MPS-2 is proposed with the elimination of six items. Although the reliability of the subscale PCP is questionable, the instrument can be used in Spanish-speaking sport for measuring perfectionism. More review and psychometric evaluation is required to improve the instrument.

\section{Acknowledgements}

This work has been done, in part, thanks to the subsidy of the code project 10485 of Programa para el Desarrollo Profesional Docente para el tipo Superior (PRODEP).

\section{REFERENCES}

[1] G. L. Flett, P. L. Hewitt. The perils of perfectionism in sports and exercise. Current Directions in Psychological Science, Vol. 14, 14-18, 2005.

[2] J. K. Gotwals, J. Stoeber, J. G. Dunn, O. Stoll. Are perfectionistic strivings in sport adaptive? A systematic review of confirmatory, contradictory, and mixed evidence. Canadian Psychology, Vol. 53, 263-279, 2012.

[3] J, Stoeber, K. Otto. Positive conceptions of perfectionism: Approaches, evidence, challenges. Personality and Social Psychology Review, Vol. 10, 295-319, 2006.

[4] G. L. Flett, P. L. Hewitt. Perfectionism: Theory, research, and treatment. Washington, D.C.: American Psychological Association, 2002.

[5] J. G. H. Dunn, J. K. Gotwals, J. Causgrove Dunn. An examination of the domain specificity of perfectionism among intercollegiate student-athletes. Personality and Individual Differences, Vol. 38, 1439-1448, 2005.

[6] J. Stoeber, F. S. Stoeber. Domains of perfectionism: Prevalence and relationships with perfectionism, gender, age, and satisfaction with life. Personality and Individual Differences, Vol. 46, No. 4, 530-535, 2009.

[7] R. O. Frost, P. Marten, C. Lahart, R. Rosenblate. The dimensions of perfectionism. Cognitive Therapy and Research, Vol. 14, 449-468, 1990.

[8] J. G. H. Dunn, J. Causgrove Dunn, D. G. Syrotiuk. Relationship between multidimensional perfectionism and goal orientation in sport. Journal of Sport and Exercise Psychology, Vol. 24, 376-395, 2002.
[9] M. H. Anshel, H. J. Eom. Exploring the dimensions of perfectionism in sport. International Journal of Sport Psychology, Vol. 34, 255-271, 2003.

[10] J. K. Gotwals, J. G. Dunn. A multi-method multi-analytic approach to establishing internal construct validity evidence: The Sport Multidimensional Perfectionism Scale 2. Measurement in Physical Education and Exercise Science, Vol. 13, 71-92, 2009.

[11] J. K. Gotwals, J. G. Dunn, J. Causgrove Dunn, V. Gamache. Establishing validity evidence for the Sport Multidimensional Perfectionism Scale-2 in intercollegiate sport. Psychology of Sport and Exercise, Vol. 11, 423-432, 2010.

[12] J. G.H. Dunn, J. Causgrove Dunn, V. Gamache, N. L. Holt. A person-oriented examination of perfectionism and slump-related coping in female intercollegiate volleyball players. International Journal of Sport Psychology, Vol. 45, 298-324, 2014.

[13] J. K. Gotwals. Perfectionism and burnout within intercollegiate sport: A person-oriented approach. The Sport Psychologist, Vol. 25, No. 4, 489-510, 2011.

[14] K. M. Sapieja, J. G. Dunn, N. L. Holt. Perfectionism and perceptions of parenting styles in male youth soccer. Journal of Sport and Exercise Psychology, Vol. 33, No. 1, 20-39, 2011.

[15] J. R. Andrade, J. R Nickenig, D. Lavallee, L. Fiorese. Adaptation and validation of the Sport Multidimensional Perfectionism Scale-2 (SMPS-2) for the Brazilian sport context. Motriz: Revista de Educação Física, Vol. 21, 125-136, 2015 .

[16] J. G. H. Dunn, J. Causgrove Dunn, V. Gamache, N.L. Holt. A person-oriented examination of perfectionism and slump-related coping in female intercollegiate volley-ball players. International Journal of Sport Psychology, Vol. 45, 298-324, 2014.

[17] J. K. Gotwals, N. Spencer-Cavaliere. Intercollegiate perfectionistic athletes' perspectives on achievement: Contributions to the understanding and assessment of perfectionism in sport. International Journal of Sport Psychology, Vol. 45, No. 4, 271-297, 2014.

[18] J. Hair, W. Black, B. Babin, R. Anderson, R. Tatham. Multivariate Data Analysis. New Jersey: Pearson Educational, 2005.

[19] R.K. Hambleton. Adaptación de tests para su uso en diferentes idiomas y culturas: Fuentes de error, posibles soluciones y directrices prácticas. In J. Muñiz (Ed.), Psicometría (pp. 207-238). Madrid: Universitas. 1996.

[20] N. Balluerka, A. Gorostiaga, I. Alonso-Arbiol, M. Haranburu. La adaptación de instrumentos de medida de unas culturas a otras: Una perspectiva práctica. Psicothema, Vol. 19, 124-133, 2007.

[21] J. Muñiz, P. Elosua, R. K. Hambleton. Directrices para la traducción y adaptación de los tests: Segunda edición. Psicothema, Vol. 25, 151-157, 2013

[22] J. W. Graham, P. E. Cumsille, E. Elek-Fiske. Methods for handling missing data. In J. A. Schinka, \& W. F. Velicer (Eds.), Handbook of psychology: Research methods in psychology (Vol. 2, pp. 87-114). Hoboken, NJ: Wile, 2003. 
[23] K.G. Jöreskog, D. Sörbom. LISREL 8.80. Lincolnwood, IL: Scientific Software International, Inc. 2006.

[24] C-P. Chou, P.M. Bentler, A. Satorra. Scaled test statistics and robust standard errors for non-normal data in covariance structure analysis: A Monte Carlo study. British Journal of Mathematical and Statistical Psychology, Vol. 44, 347-357, 1991.

[25] P.M. Bentler. On tests and indices for evaluating structural models. Personality and Individual Differences, 42, 825-829, 2007.

[26] S.G. West, J.F. Finch, P.J. Curran. Structural equation models with nonnormal variables: Problems and remedies. In R. H. Hoyle (Ed.), Structural equation modeling: Concepts, issues and applications (pp. 56-75). Newbury Park, CA: Sage. 1995.

[27] A. Satorra, P.M. Bentler. Corrections to test statistics and standard errors in covariance structure analysis. In A. von Eye \& C. C. Clogg (Eds.), Latent variables analysis: Applications for developmental research (pp. 399-419). Thousand Oaks, CA: Sage, 1994

[28] L. Hu, P.M. Bentler. Evaluating model fi t. In R. H. Hoyle (Ed.), Structural equation modeling: Issues, concepts, and applications (pp. 76-99). Newbury Park, CA: SAGE, 1995.

[29] L. Hu, P.M. Bentler. Cut-off criteria for fit indexes in covariance structure analysis: conventional criteria versus new alternatives. Structural Equation Modeling: A Multidisciplinary Journal, Vol. 6, No. 1, 1-55, 1999.
[30] E. Mullan, D. Markland, D. K. Ingledew. A graded conceptualisation of self-determination in the regulation of exercise behaviour: development of a measure using confirmatory factor analytic procedures. Personality and Individual Differences, Vol. 23, 745-752, 1997.

[31] K. F. Widaman. Hierarchically nested covariance structure models for multitrait-multimethod data. Applied Psychological Measurement, Vol. 9, 1-26, 1985

[32] G. W. Cheung, R. B. Rensvold. Evaluating goodness-of-fit indexes for testing measurement invariance. Structural Equation Modeling, Vol. 9, 235-255, 2002.

[33] R. B. Kline. Principles and practice of structural equation modeling. New York, NY: Guilford. 2005.

[34] J. G. Dunn, J. C. Dunn, D. G. Syrotuik. Relationship between multidimensional perfectionism and goal orientations in sport. Journal of Sport and Exercise Psychology, Vol. 24, No. 4, 376-395, 2002.

[35] J. G. Dunn, J. C. Dunn, J. K. Gotwals, J. K. Vallance, J. M. Craft, D. G. Syrotuik. Establishing construct validity evidence for the Sport Multidimensional Perfectionism Scale. Psychology of Sport and Exercise, Vol. 7, 57-79, 2006.

[36] J.G. Dunn, J.K. Gotwals, J.C. Dunn, A.M. Selzler, M.R. Lizmore, M. Vaartstra, ..., V.E. Gamache. A multi-sample investigation of the higher-order latent dimensionality of the Sport-Multidimensional Perfectionism Scale-2. Psychology of Sport and Exercise, Vol. 27, 150-156, 2016. 